\title{
Erratum to: Looking forward to new targeted treatments for chronic spontaneous urticaria
}

Emek Kocatürk ${ }^{1 *}$ (D) Marcus Maurer ${ }^{2}$, Martin Metz ${ }^{2}$ and Clive Grattan ${ }^{3}$

\section{Erratum to: Clin Transl Allergy (2017) 7:1 DOI 10.1186/s13601-016-0139-2}

Information from the manufacturer of the topical intervention in the GSK2646264 trial outlined in this review [1] indicates that the half-life of the product has not been established with certainty on the available data.

\section{Author details}

1 Department of Dermatology, Okmeydanı Training and Research Hospital, Istanbul, Turkey. ${ }^{2}$ Department of Dermatology and Allergy, Charité - Universitäts medizin, Berlin, Germany. ${ }^{3}$ St John's Institute of Dermatology, Guy's Hospital, London, UK.

The online version of the original article can be found under doi:10.1186/s13601-016-0139-2.

Received: 13 March 2017 Accepted: 13 March 2017

Published online: 03 April 2017

\section{Reference}

1. Kocatürk E, Maurer M, Metz M, Grattan C. Looking forward to new targeted treatments for chronic spontaneous urticaria. Clin Transl Allergy. 2017;7:1.

\footnotetext{
*Correspondence: dremekozgur@gmail.com

1 Department of Dermatology, Okmeydanı Training and Research Hospital, Istanbul, Turkey

Full list of author information is available at the end of the article
} 